---Supporting Information---

\title{
Photocatalytic Nitroaromatic Prodrug Activation by Functionalized Gold Nanoclusters
}

Dajiao Cheng, Rong Liu, Limei Tian, Quan Zhou, Fushuang Niu, Yinghong Yue*, Ke

$$
H u^{*}
$$

Department of Chemistry, Fudan University, Shanghai 200433, P. R. China

* Corresponding author. E-mail: yhyue@fudan.edu.cn, khu@fudan.edu.cn 

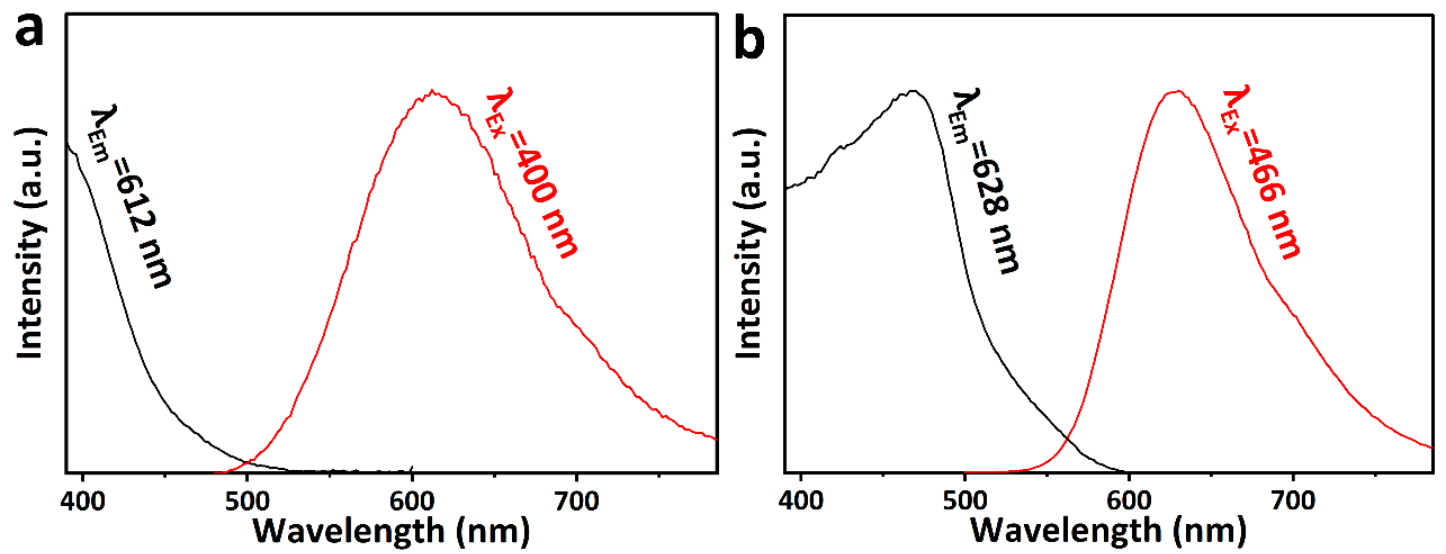

Figure S1. Fluorescence excitation spectra (black line) and emission spectra (red line) of (a) Au NC and (b) Au-PS in DW.

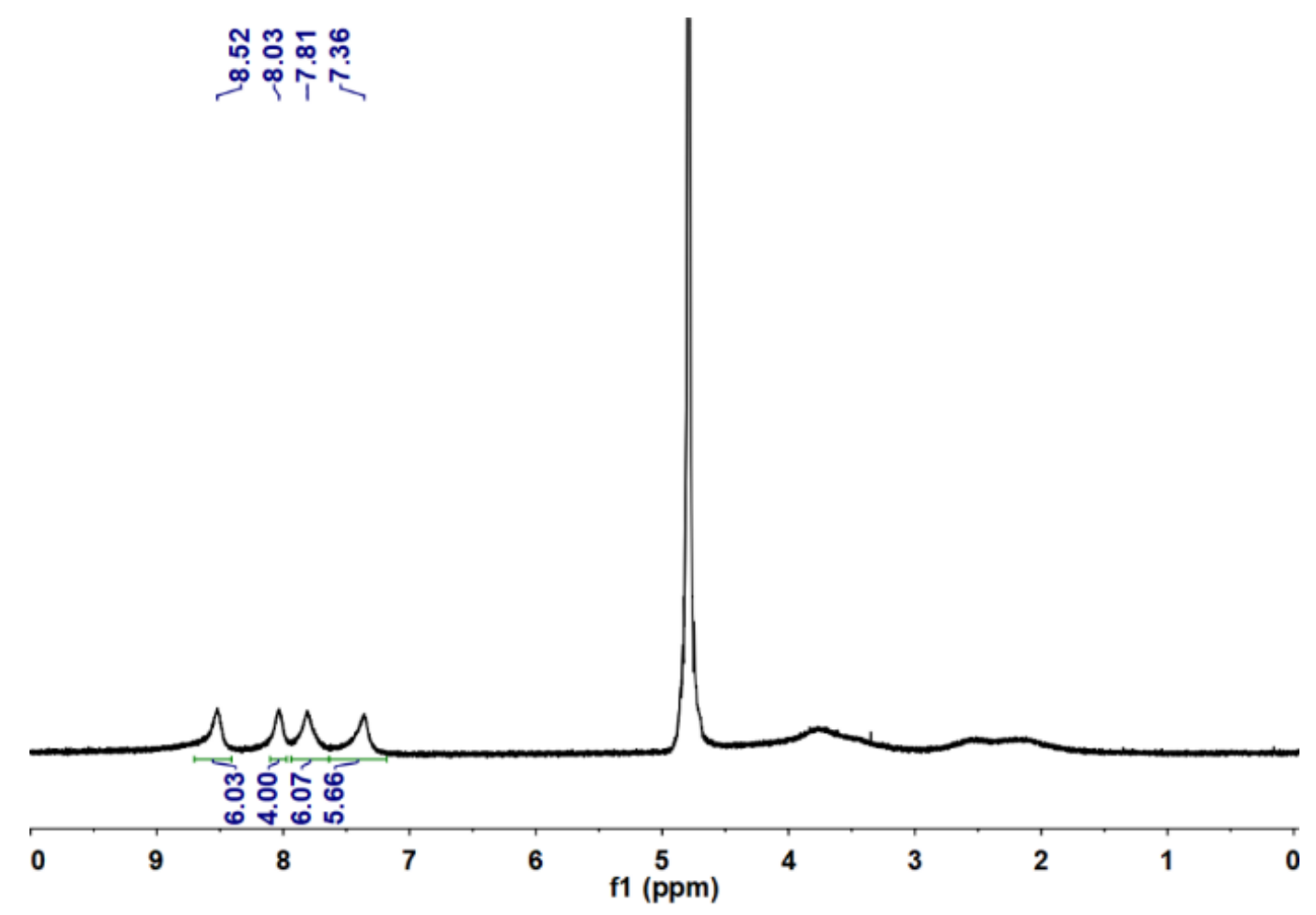

Figure S2. ${ }^{1} \mathrm{H}-\mathrm{NMR}$ spectra of Au-PS. 


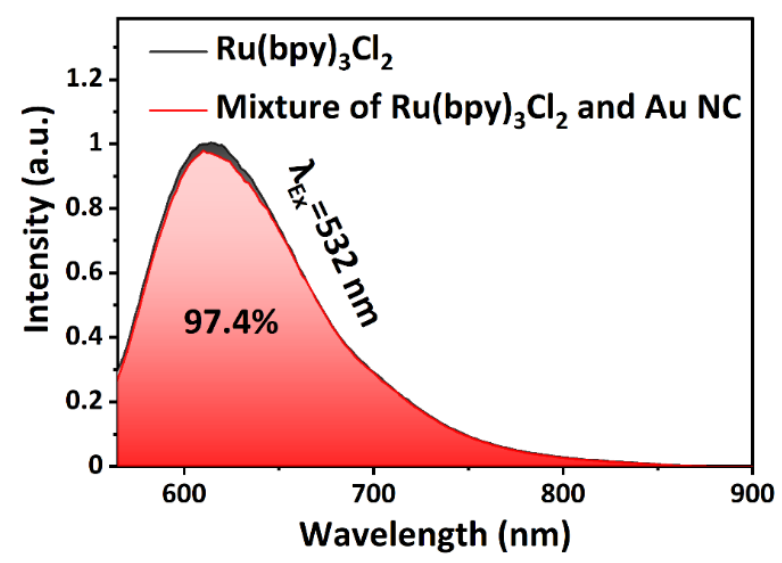

Figure S3. Steady state photoluminescence spectra of $\mathrm{Ru}(\mathrm{bpy})_{3} \mathrm{Cl}_{2}$ (black) and mixture of the same concentration of $\mathrm{Ru}(\mathrm{bpy})_{3} \mathrm{Cl}_{2}$ and $\mathrm{Au} \mathrm{NC}$ (red line) following photoexcitation at $532 \mathrm{~nm}$. The percentage number shown in the figure represents the ratio of the red region to the black region.
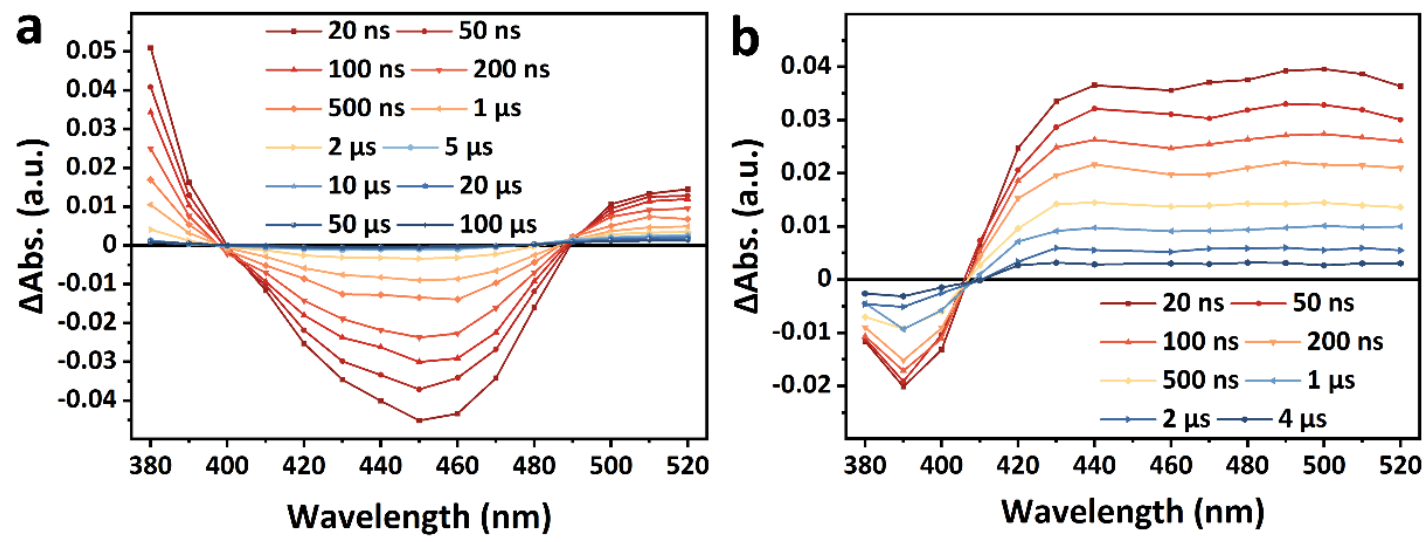

Figure S4. Transient absorption difference spectra of (a) Au-PS after $532 \mathrm{~nm}$ pulsed laser excitation and (b) $\mathrm{Au} \mathrm{NC}$ after $450 \mathrm{~nm}$ pulsed laser excitation in aqueous solution at indicated delay times. 


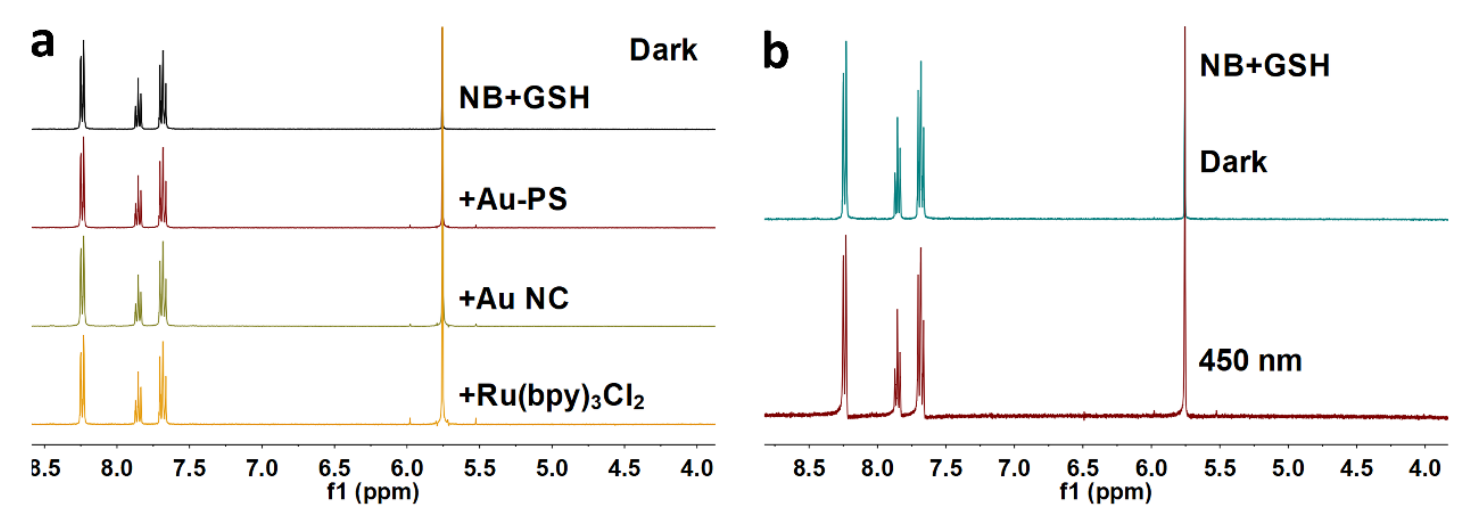

Figure S5. (a) ${ }^{1} \mathrm{H}-\mathrm{NMR}$ analysis of photocatalytic reduction of nitrobenzene (NB) by Au-PS, $\mathrm{Au} \mathrm{NC}$ or $\mathrm{Ru}(\mathrm{bpy}){ }_{3} \mathrm{Cl}_{2}$ in the dark under hypoxic condition, respectively. (b) ${ }^{1} \mathrm{H}-\mathrm{NMR}$ spectra of photocatalytic reduction of NB in the absence of catalyst.

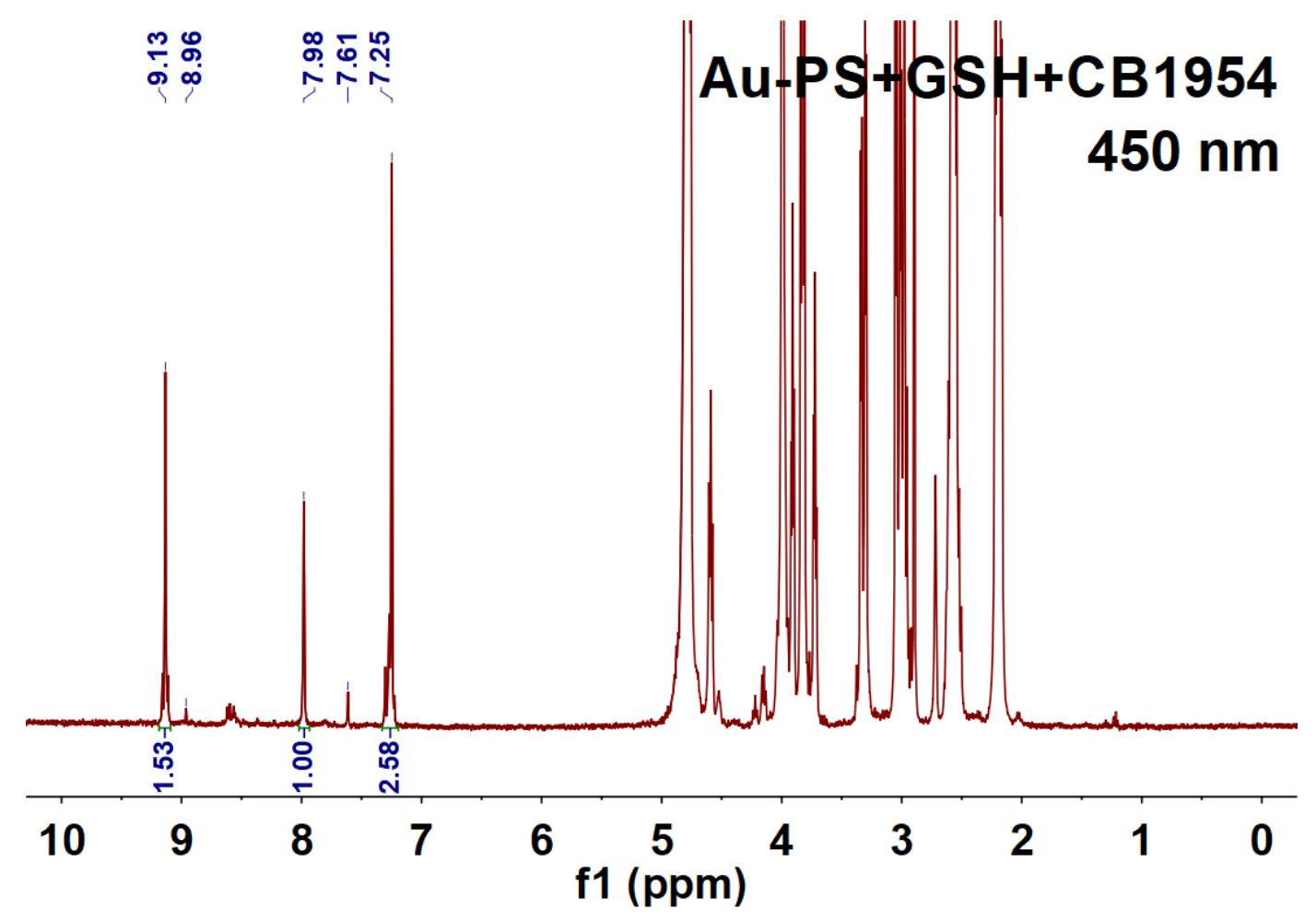

Figure S6. ${ }^{1} \mathrm{H}-\mathrm{NMR}$ analysis of photocatalytic reduction of CB1954 by Au-PS under hypoxic condition. 

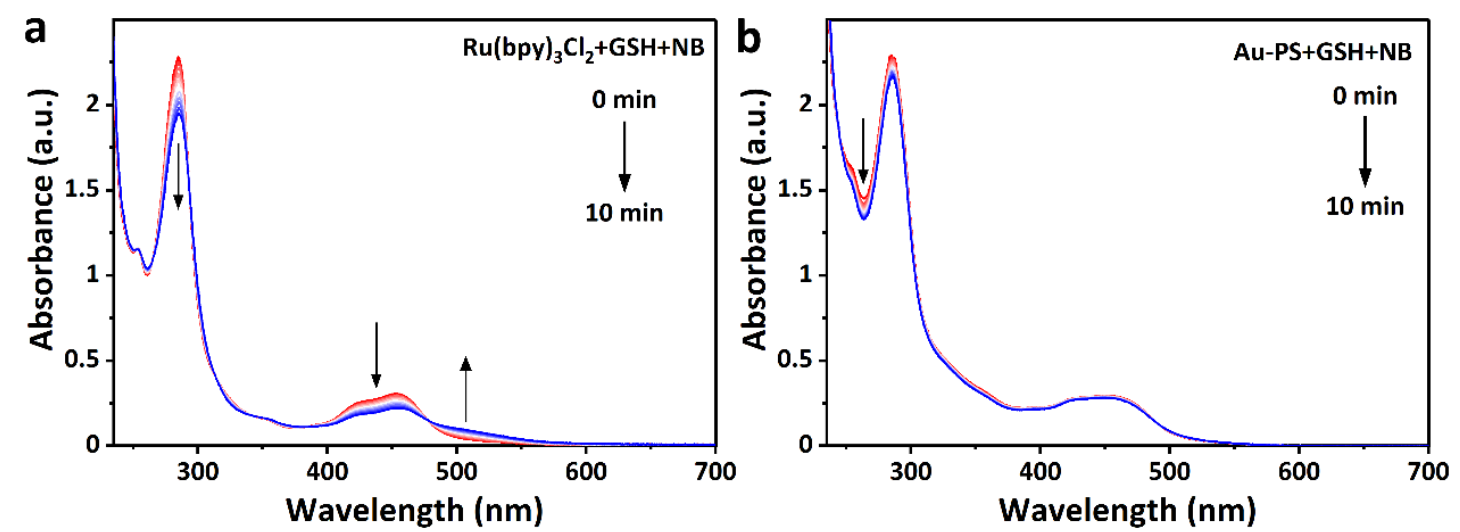

Figure S7. UV-vis absorption spectra of photocatalytic reduction of NB by (a) $\mathrm{Ru}(\mathrm{bpy})_{3} \mathrm{Cl}_{2}$ and (b) Au-PS under $450 \mathrm{~nm}$ irradiation in hypoxia.
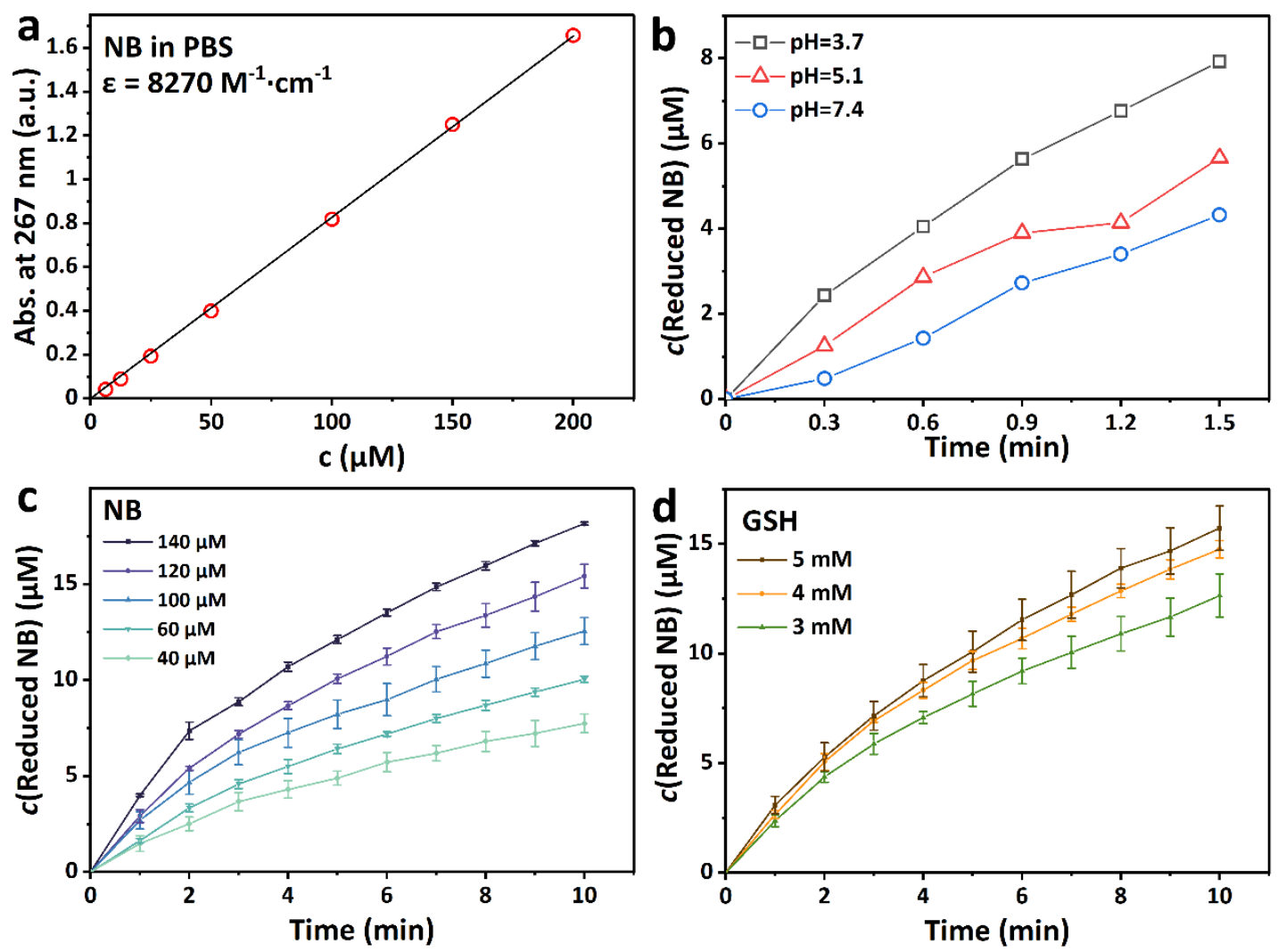

Figure S8. (a) Molar extinction coefficient of NB at $267 \mathrm{~nm}$ in PBS buffer containing DMSO. The factors affecting the photoreduction rate of NB: (b) $\mathrm{pH}$ of the reaction solution, the concentration of (c) NB and (d) GSH. 


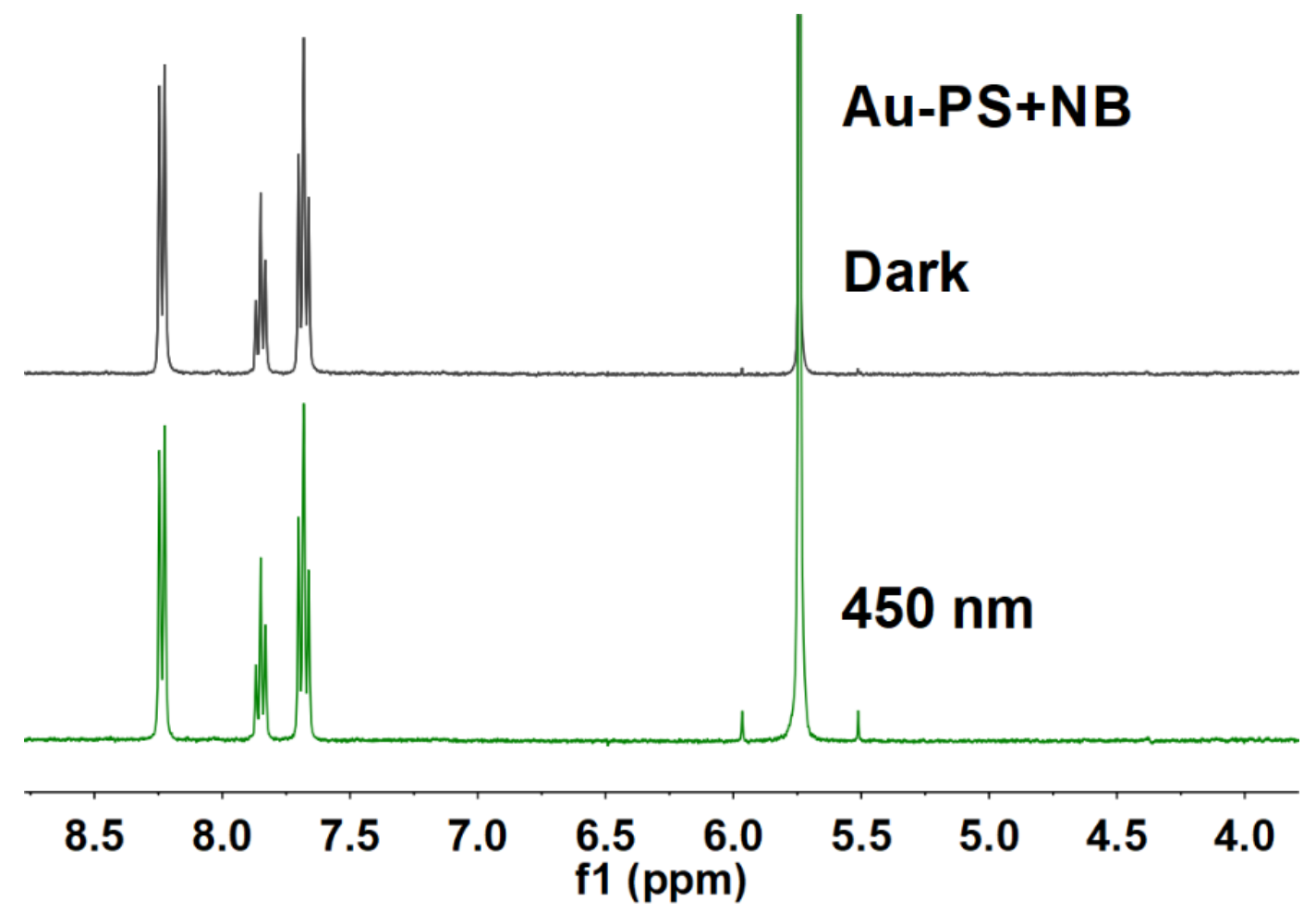

Figure S9. ${ }^{1} \mathrm{H}-\mathrm{NMR}$ spectra of photocatalytic reduction of NB by Au-PS in the absence of GSH.

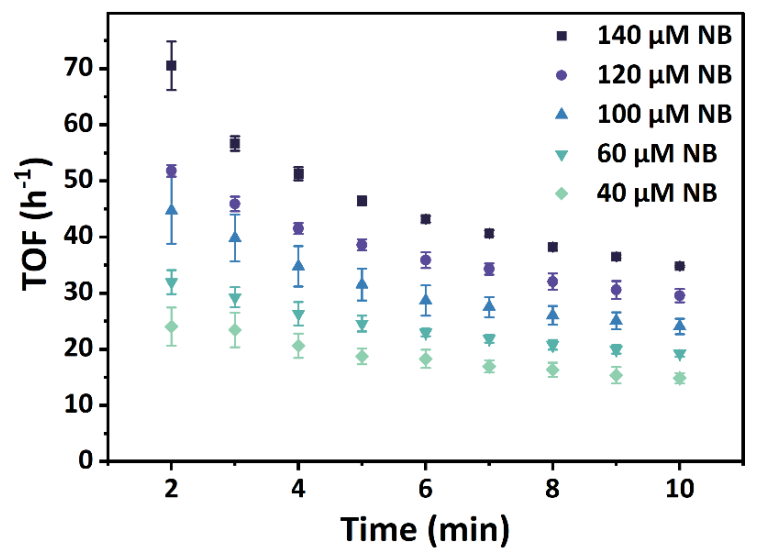

Figure S10. Dependence of turnover frequencies (TOF) on NB concentration, photocatalyzed with Au-PS $(3.13 \mu \mathrm{M})$ and monitored by UV-vis spectrophotometer. With increasing NB/ Au-PS ratio, the TOF increased. 

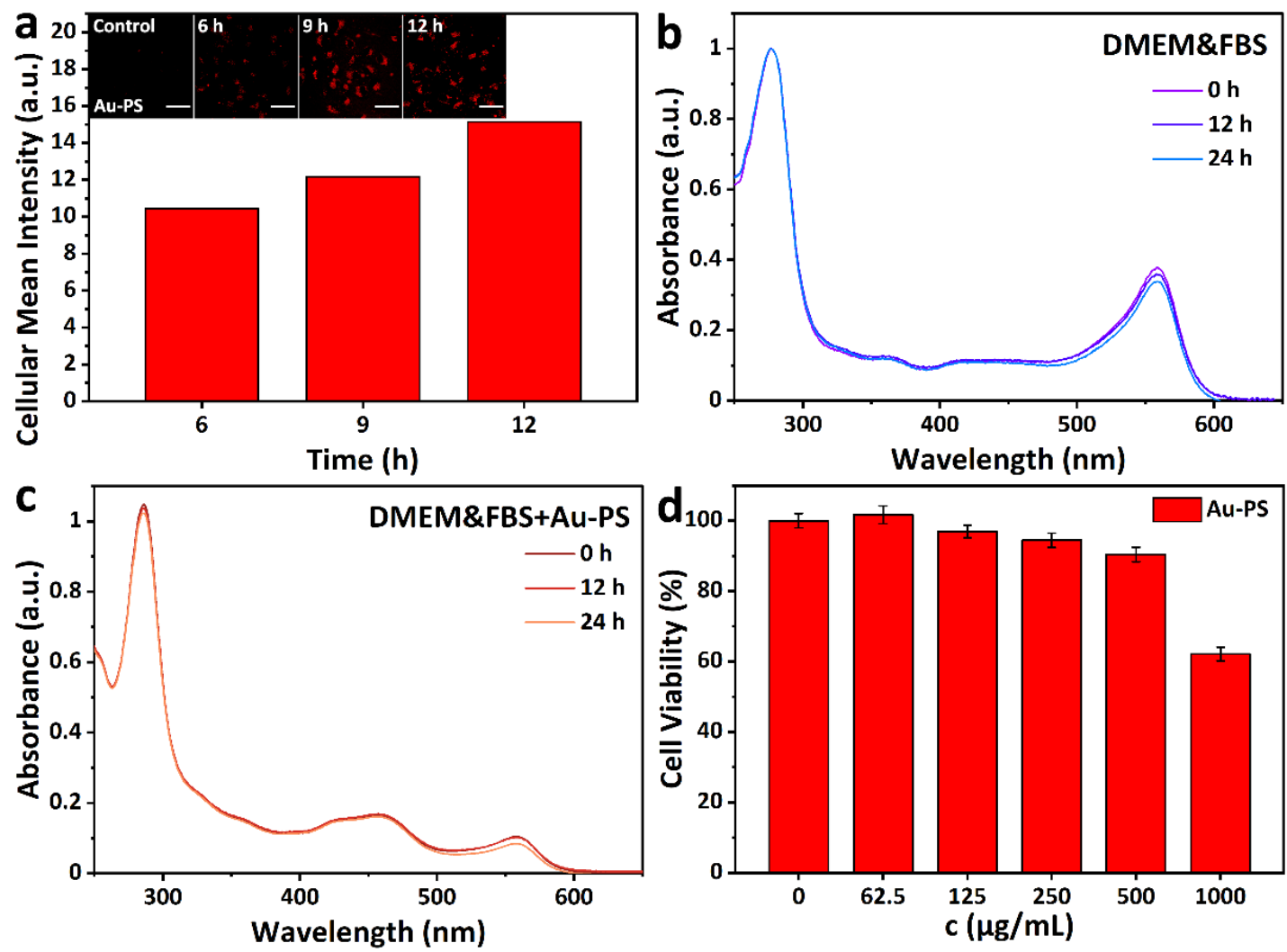

Figure S11. (a) Mean fluorescence intensity of Au-PS in Hela cells at various incubation times. Inset: Intracellular Au-PS analyzed by confocal laser scanning microscope (CLSM). $\lambda_{\mathrm{ex}}=488 \mathrm{~nm}, \lambda_{\mathrm{em}}=620 \pm 50 \mathrm{~nm}$. Scale bar $=50 \mu \mathrm{m}$. UV-vis spectra of (b) cell culture medium (DMEM) containing Fetal Bovine Serum (FBS) and (c) Au-PS dissolved in cell culture medium containing FBS at $0 \mathrm{~h}, 12 \mathrm{~h}$ and $24 \mathrm{~h}$. (d) Cell viability of Hela cells after incubated with different concentrations of Au-PS for $24 \mathrm{~h}$.
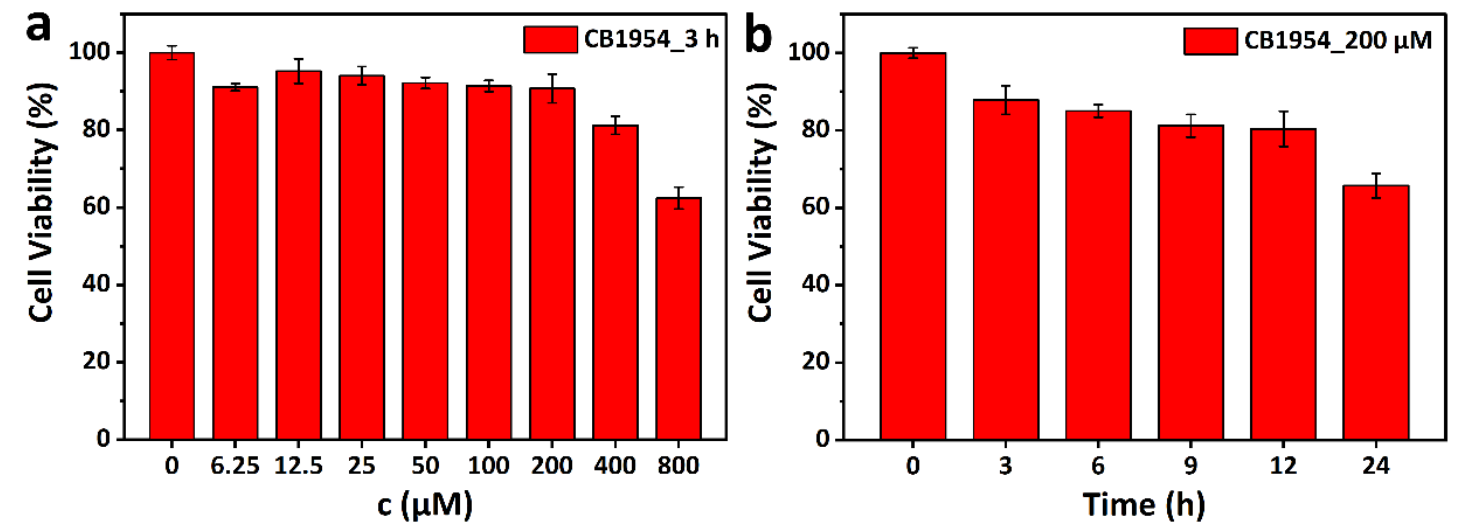
Figure S12. Cytotoxicity of Hela cells after incubated with (a) different concentrations of 5-(aziridin-1-yl)-2,4-dinitrobenzamide (CB1954) for $3 \mathrm{~h}$ and (b) $200 \mu \mathrm{M}$ of CB1954 following different incubation times.

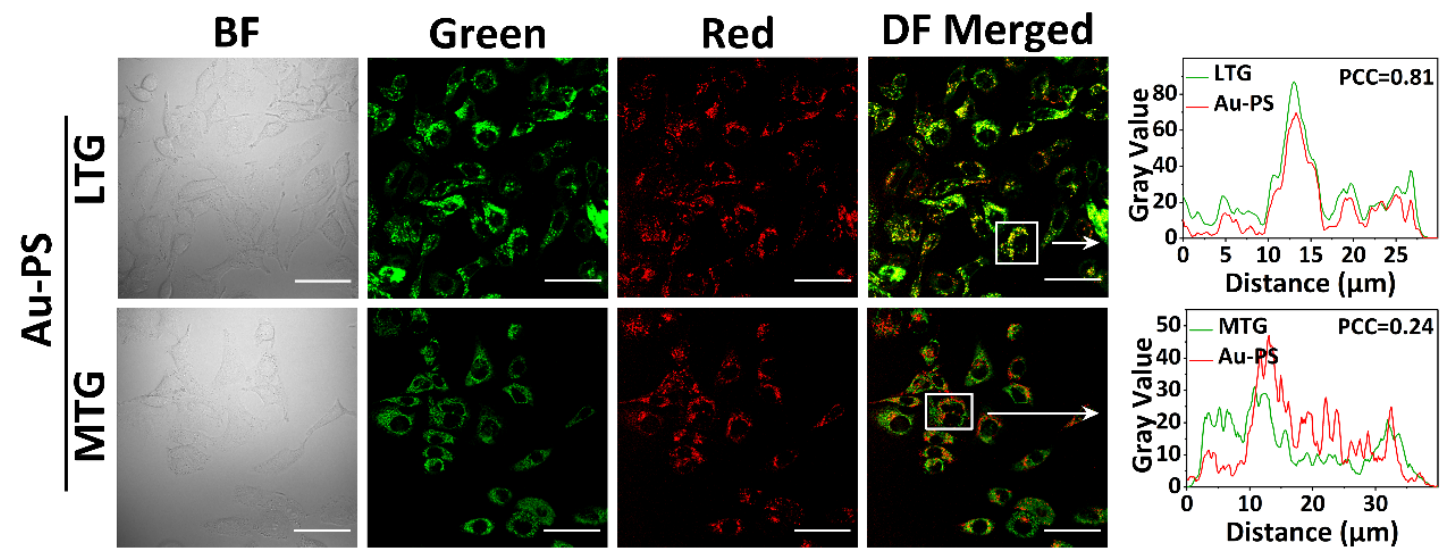

Figure S13. Live-cell confocal luminescence imaging of Au-PS co-stained with MitoTracker Green (MTG) or Lyso-Tracker Green (LTG) in A549 cells. Yellow showed the overlap of green and red. The intracellular fluorescence distribution and Pearson's correlation coefficient (PCC) were from the cells located within the rectangles in white.

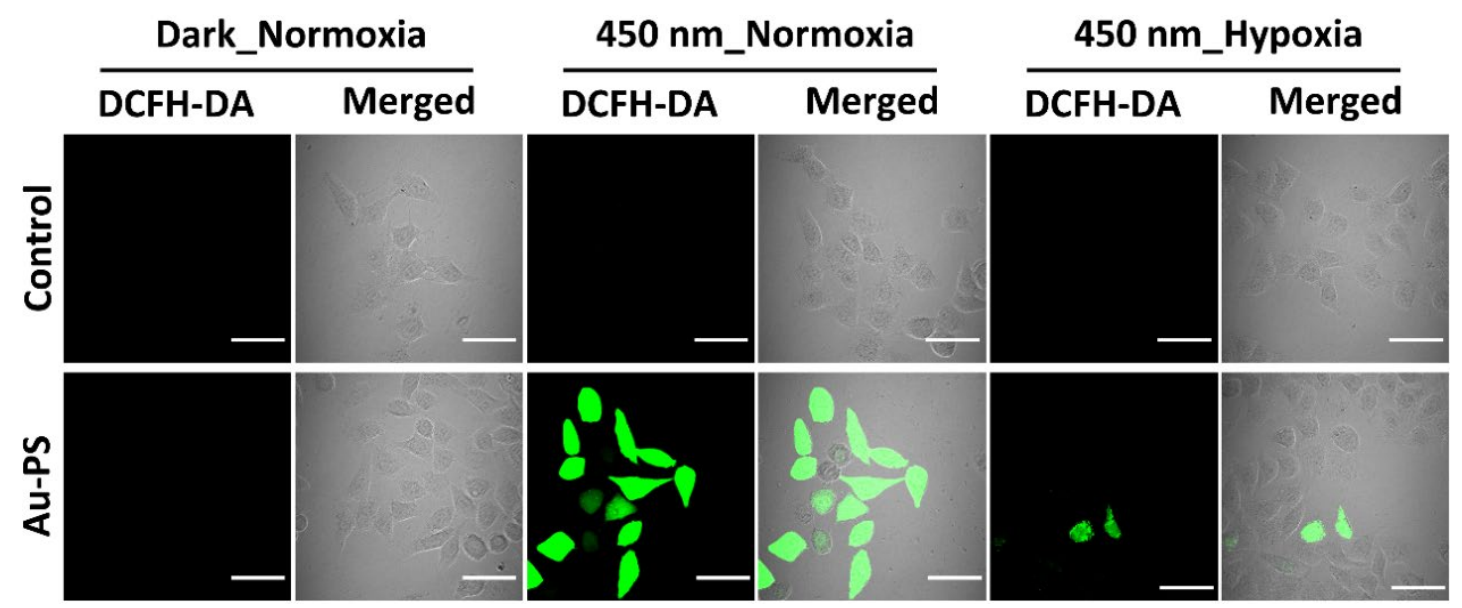

Figure S14. Intracellular ROS produced by Au-PS under $450 \mathrm{~nm}$ light both in normoxia and hypoxia was detected by 2',7'-Dichlorofluorescein-diacetate (DCFH-DA) in Hela 
cells and observed by CLSM. Scale bar $=50 \mu \mathrm{m}$.

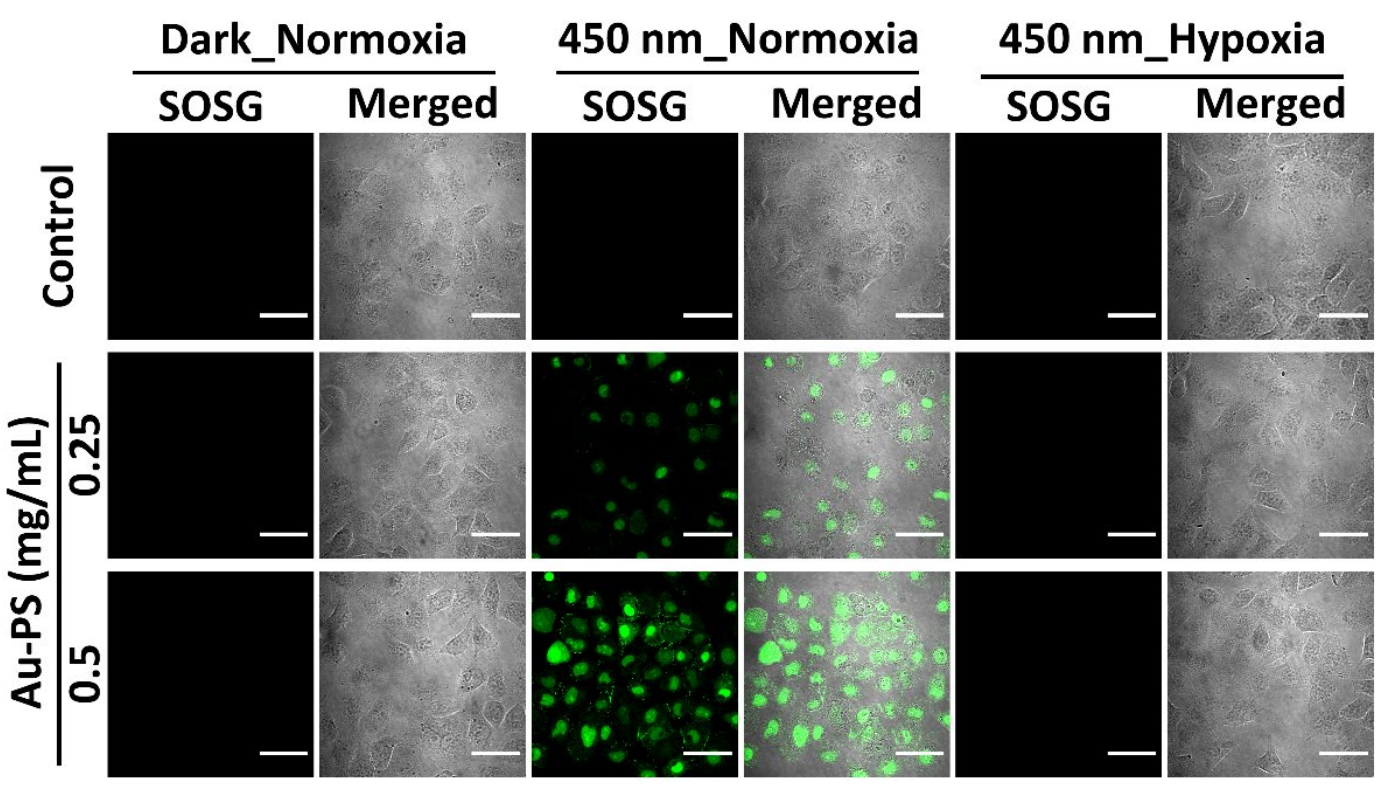

Figure $\mathrm{S} 15 .{ }^{1} \mathrm{O}_{2}$ generated by different concentrations of Au-PS with irradiation both in normoxia and hypoxia in Hela cells was determined by staining with singlet oxygen sensor green (SOSG) using CLSM. Scale bar=50 $\mu \mathrm{m}$.

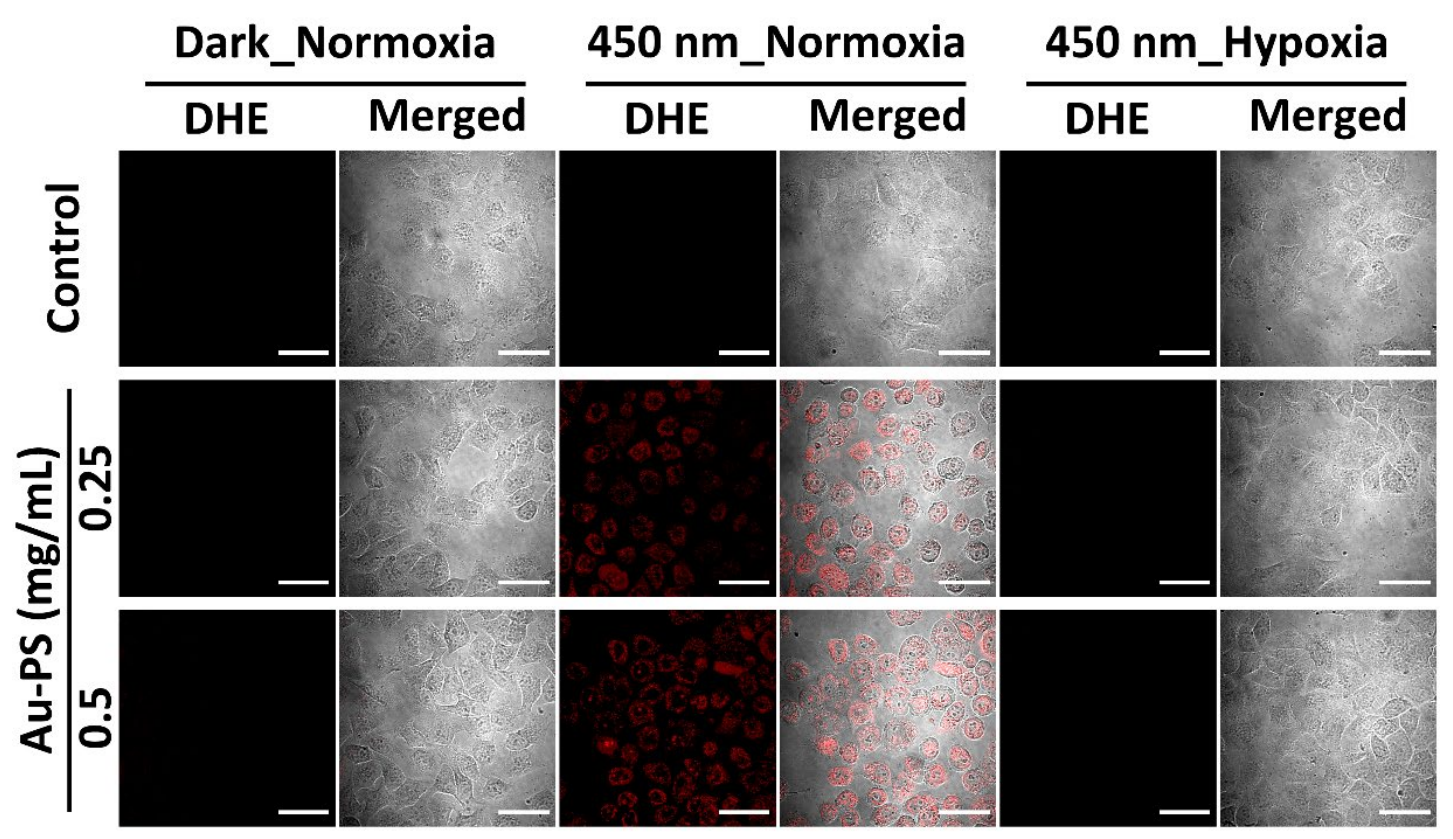

Figure $\mathrm{S} 16 . \mathrm{O}_{2}^{-\bullet}$ generated by different concentrations of Au-PS under irradiation both 
in normoxia and hypoxia in Hela cells was determined by staining with dihydroethidium (DHE) using CLSM. Scale bar $=50 \mu \mathrm{m}$.
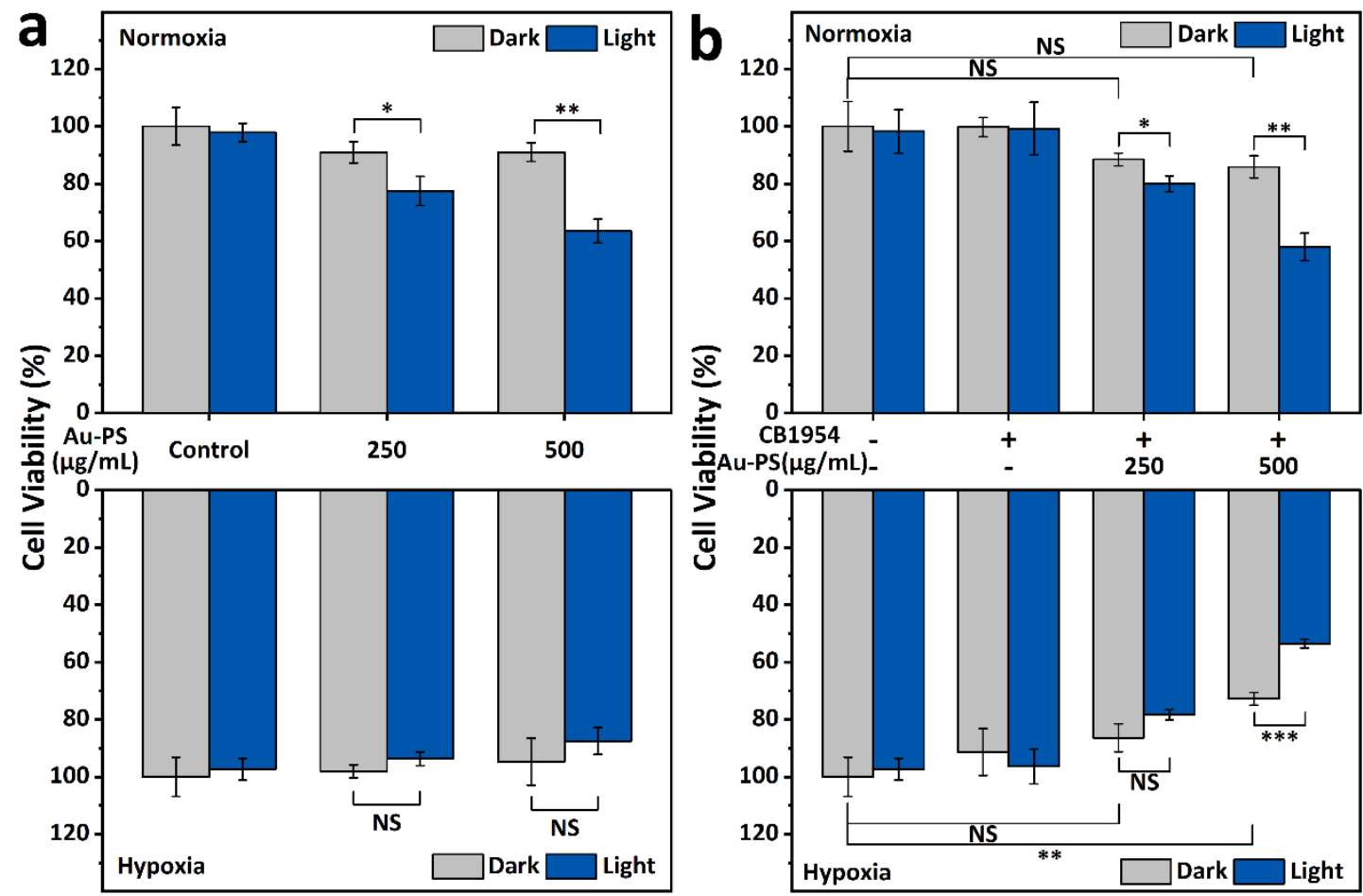

Figure S17. (a) Cell viability of A549 cells incubated with different concentrations of Au-PS under dark or light in normoxia and hypoxia. (b) Cytotoxicity of A549 cells cocultured with or without Au-PS pretreatment following with CB1954 in the dark or under irradiation in normoxia and hypoxia. For comparison, the control group was not co-incubated with the prodrug CB1954 and Au-PS. The data were expressed as mean \pm S.D. $* \mathrm{P}<0.05, * * \mathrm{P}<0.01$, and $* * * \mathrm{P}<0.001$ determined by one-way ANOVA with Tukey post-test. $\alpha=0.05$. NS stands for not significant. 

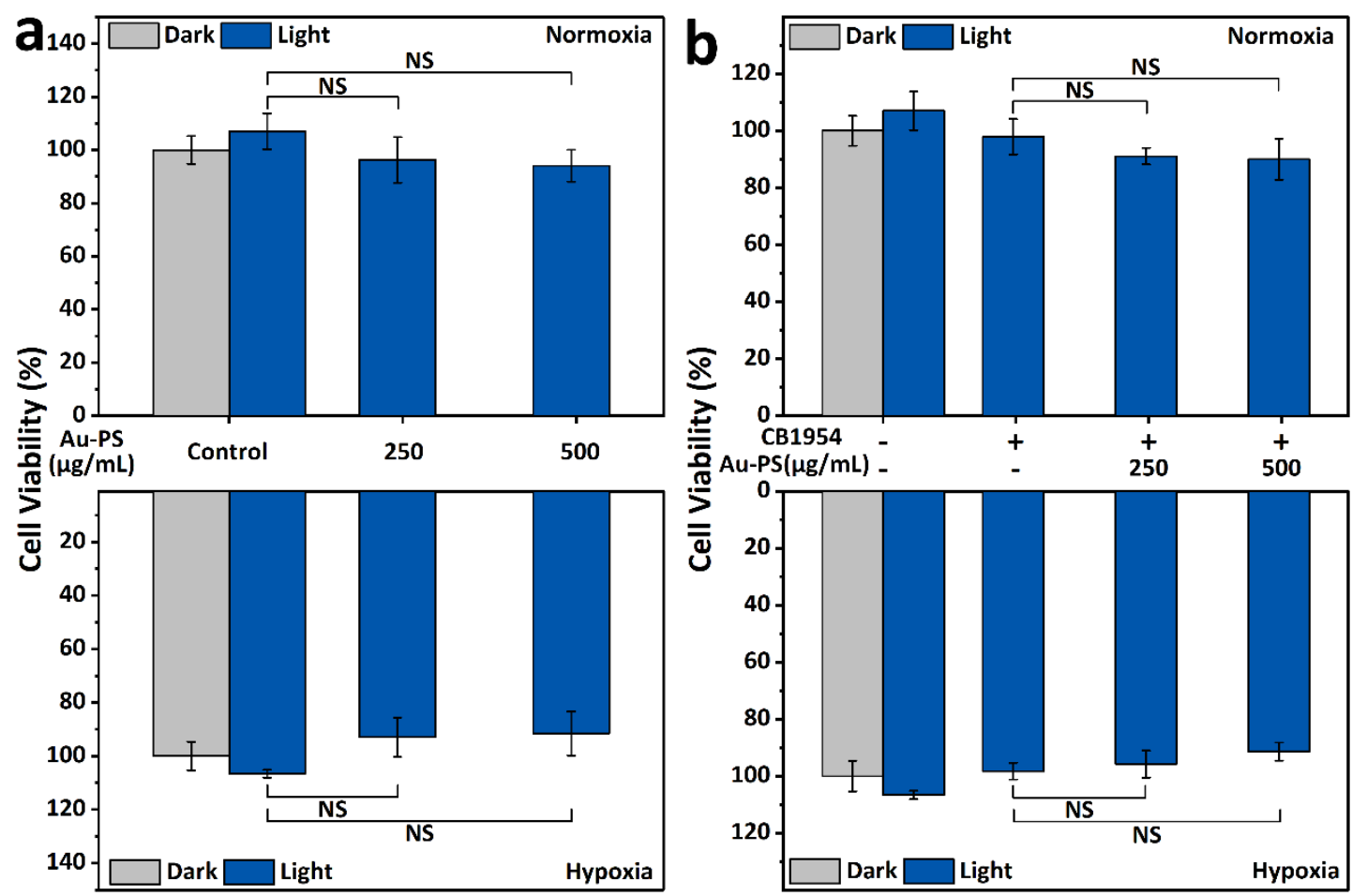

Figure S18. (a) Cell viability of HL-7702 cells incubated with different concentrations of Au-PS under dark or light in normoxia and hypoxia. (b) Cytotoxicity of HL-7702 cells co-cultured with or without Au-PS pretreatment following with CB1954 in the dark or under irradiation in normoxia and hypoxia. For comparison, the control group was not co-incubated with the prodrug CB1954 and Au-PS. NS stands for not significant.

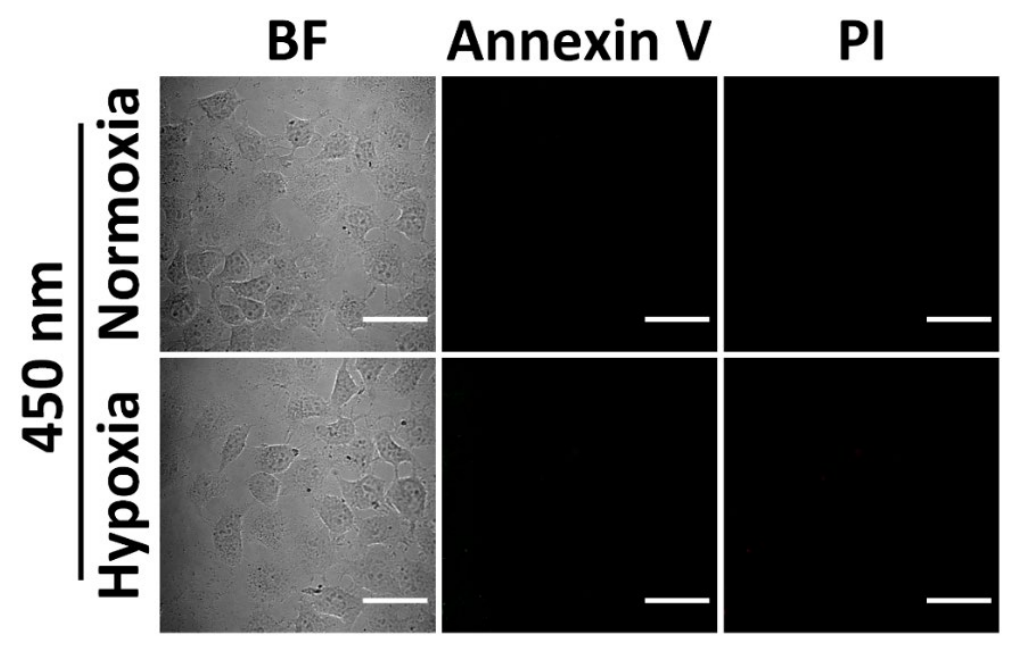


Figure S19. Untreated Hela cells in the dark or with $450 \mathrm{~nm}$ irradiation in normoxia or hypoxia with Annexin V-FITC/PI dual staining in the dark or with $450 \mathrm{~nm}$ irradiation. Scale bar $=50 \mu \mathrm{m}$.

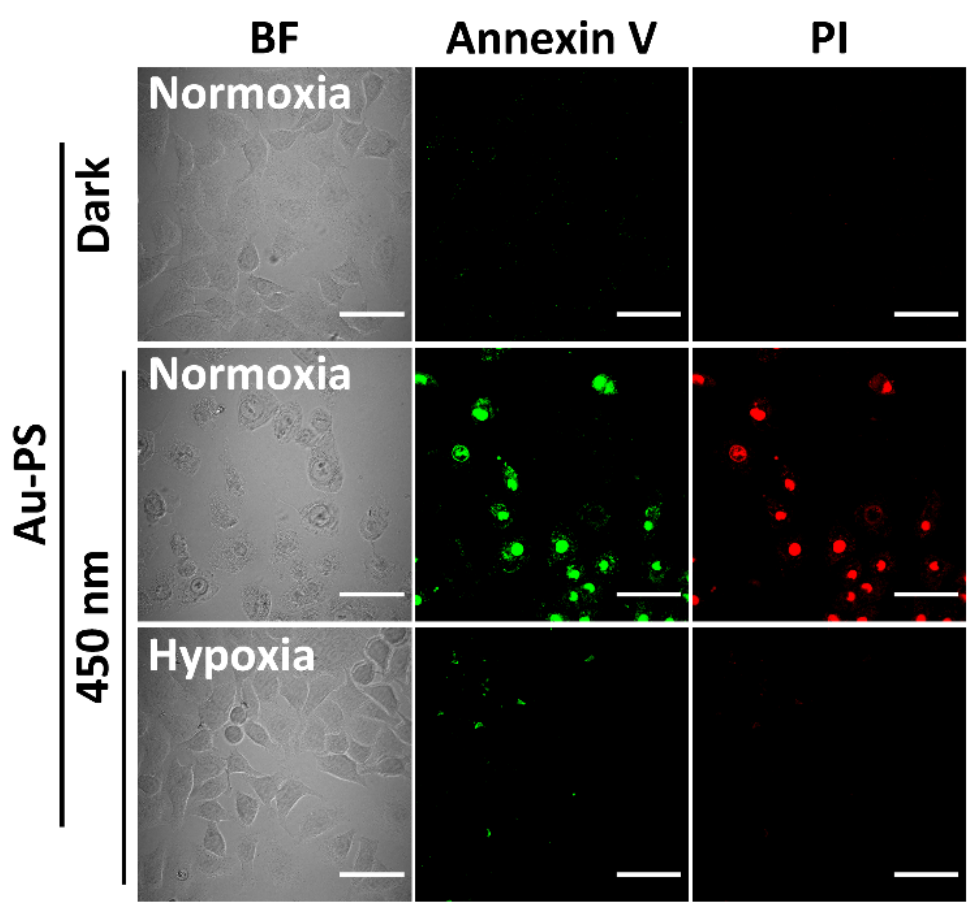

Figure S20.Assay of apoptosis with Annexin V-FITC/propidium iodide (PI)-stained Hela cells treated with Au-PS in the dark or under irradiation in normoxia or hypoxia. Scale bar $=50 \mu \mathrm{m}$. 


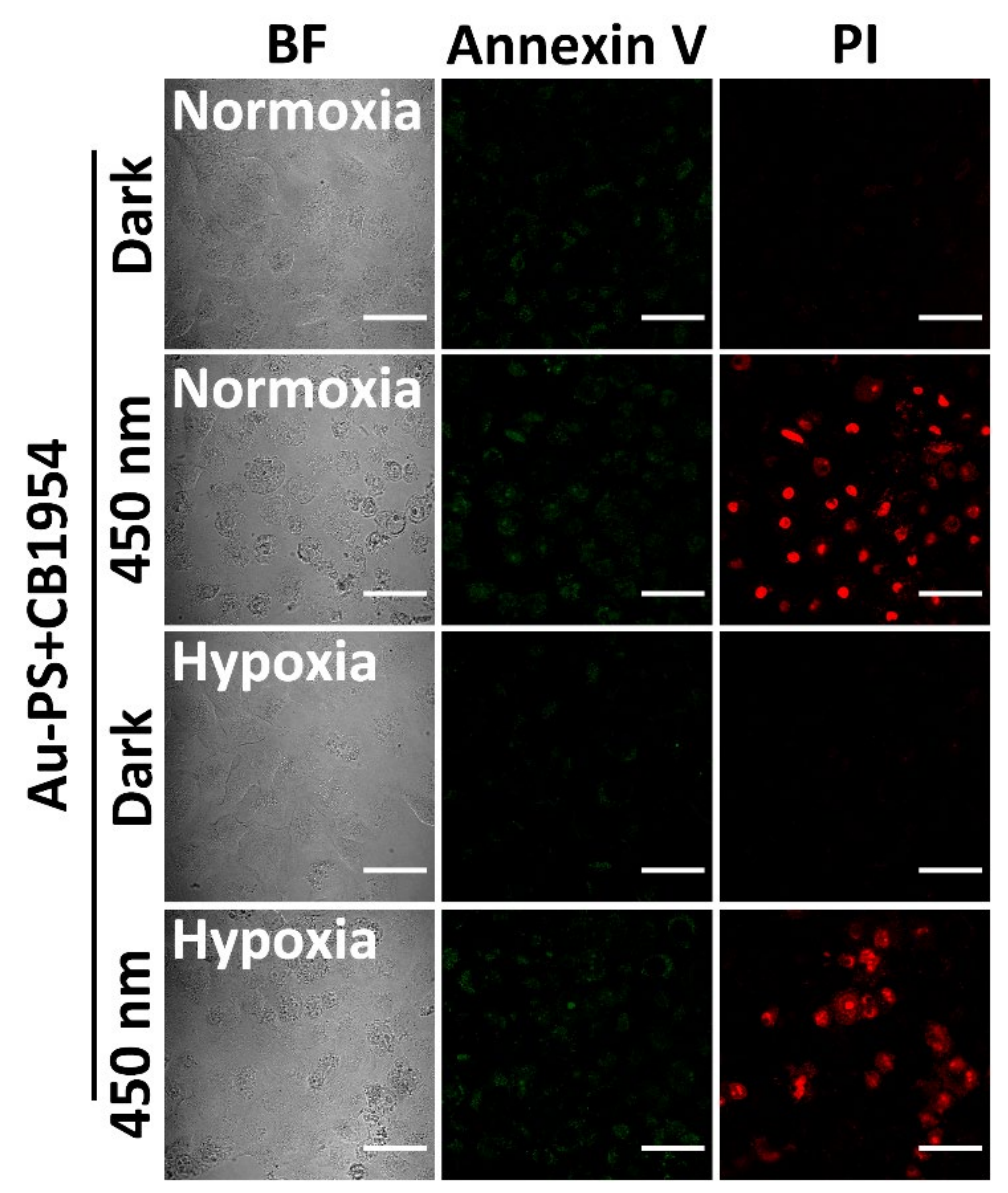

Figure S21. Assay of apoptosis with Annexin V-FITC/PI-stained Hela cells treated with Au-PS and CB1954 in the dark or under irradiation in normoxia or hypoxia. Scale bar $=50 \mu \mathrm{m}$.

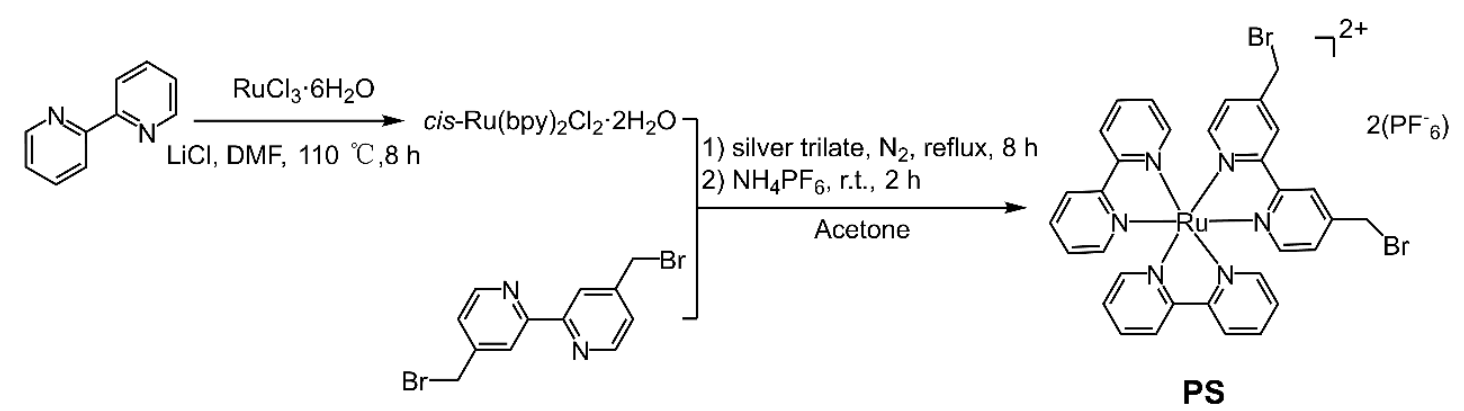

Figure S22. Synthesis of $\quad\left[\mathrm{Ru}^{\mathrm{II}}\left(2,2^{\prime}\right.\right.$ '-bipyridyl)2(4,4'-bis(bromomethyl)-2,2'bipyridyl)]( $\left.\mathrm{PF}_{6}\right)_{2}(\mathrm{PS})$. 


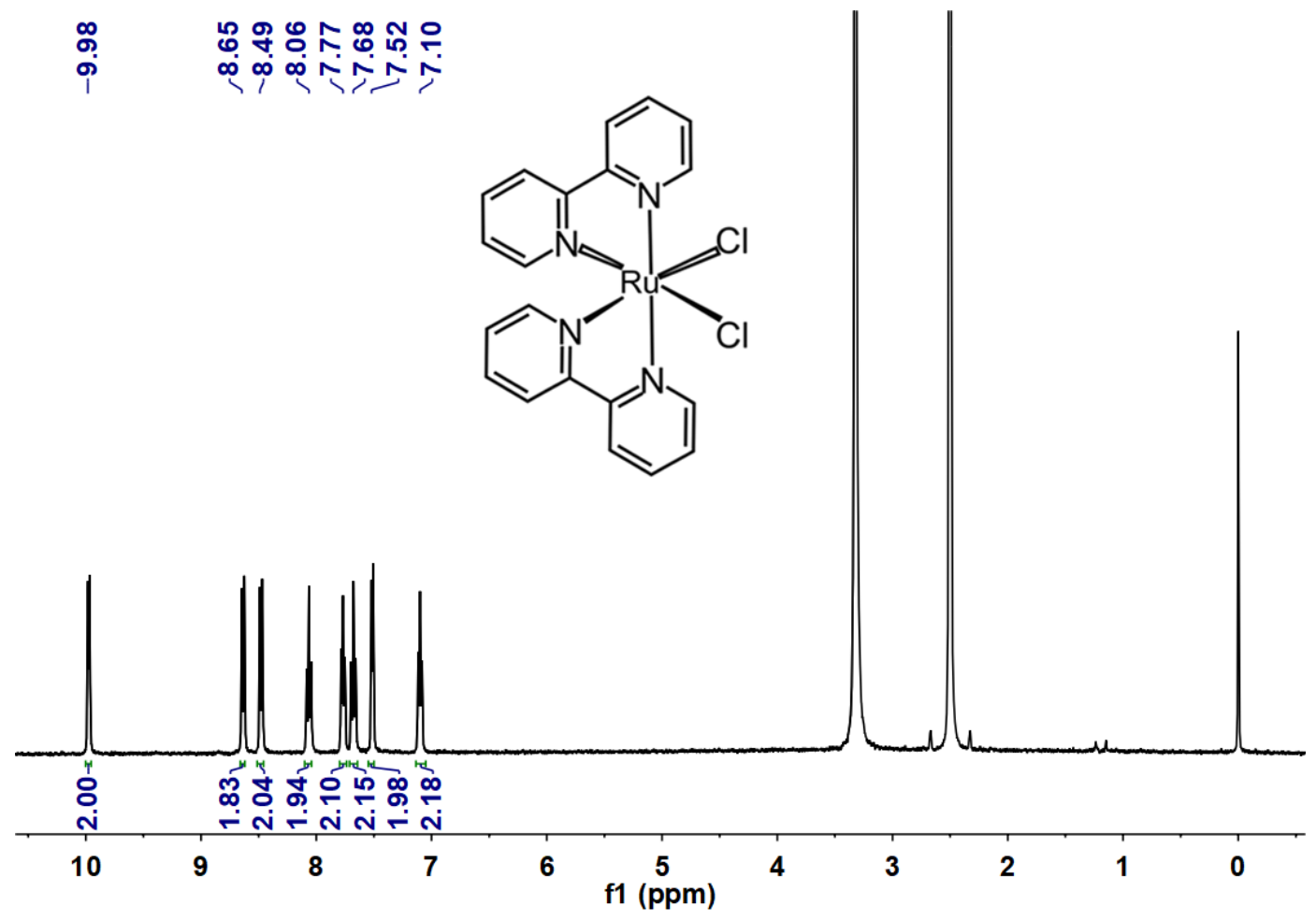

Figure S23. ${ }^{1} \mathrm{H}-\mathrm{NMR}$ spectra of $\mathrm{Ru}\left(\right.$ bipyridyl) ${ }_{2} \mathrm{Cl}_{2} \cdot \mathrm{H}_{2} \mathrm{O}$.

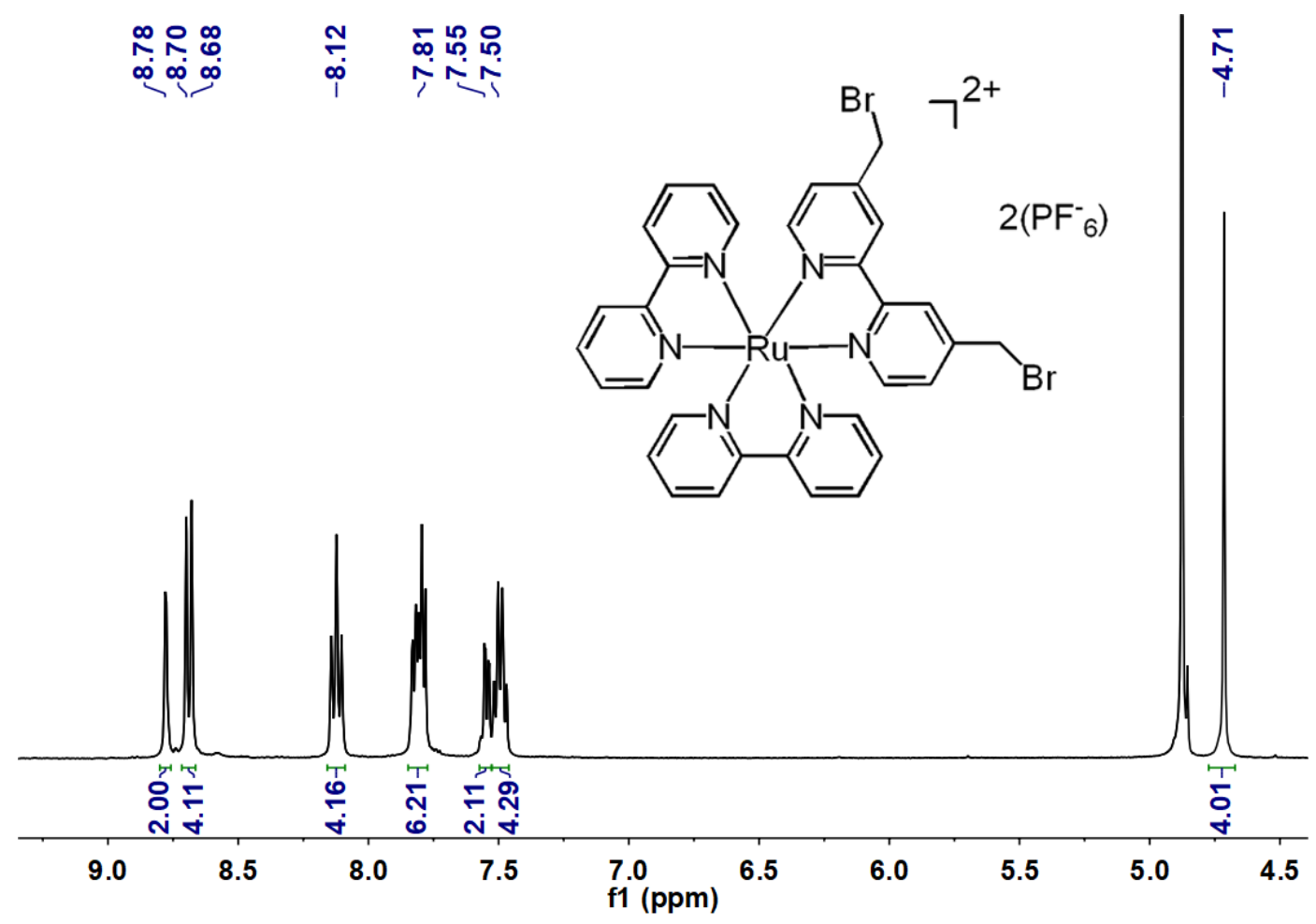

Figure S24. ${ }^{1} \mathrm{H}-\mathrm{NMR}$ spectra of PS. 